Review Article

\title{
Coronary angioplasty
}

\author{
I.C. Cooper, M. Signy, M.M. Webb-Peploe and D.J. Coltart \\ Department of Cardiology, St Thomas' Hospital, Lambeth Palace Road, London SE1, UK.
}

\section{Historical perspective}

Techniques for selective coronary arteriography were developed in the late 1950s and 1960s. ${ }^{1-4}$ Attempts at myocardial revascularization had been performed before this time, but it was not until the development of selective coronary arteriography in 1964 that present-day techniques of aorto-coronary bypass surgery were first used. ${ }^{5,6}$ In the same year Dotter \& Judkins ${ }^{7}$ described a method of dilating atherosclerotic lesions in peripheral arteries using a co-axial catheter system. In the early 1970 s Gruentzig devised an inflatable balloon for dilatation of peripheral arterial lesions and in 1977 successfully performed the first percutaneous transluminal coronary angioplasty (PTCA). ${ }^{8}$

Following this initial report PTCA has rapidly become commonplace in cardiac units throughout the world. In 1983 Gruentzig reported his first 1000 cases $^{9}$ and in 1984 the National Heart, Lung, and Blood Institute (NHLBI) PTCA Registry reported the results of 3079 patients treated by 105 centres. ${ }^{10}$ In this country a number of centres now have individual experience of over 300 cases.

Present techniques are similar to the initial method of Gruentzig, but more recent developments, such as that of the steerable guide wire, and the low profile balloon, together with increasing operator experience have lead to a primary success rate in excess of $90 \%$ in some centres. ${ }^{9}$ These technical improvements have made lesions in all three major coronary arteries accessible to the balloon. " Early experience was limited mainly to single lesion dilatation in patients with stable angina. Increasingly, PTCA is being performed in more complex situations, such as multiple vessel disease, unstable angina, following acute myocardial infarction and in elderly patients. Most recently there have been reports of the use of percutaneous laser-assisted angioplasty in man..$^{12,13}$

Correspondence: I.C. Cooper, M.B., B.S., M.R.C.P.

Received: 27 November 1986

\section{Pathology}

The exact mechanism by which balloon dilatation relieves stenosis is poorly understood. The atherosclerotic plaque tends to cause luminal narrowing by a splinting and underlying contraction of the arterial wall rather than by volume displacement of the lumen by the lesion. ${ }^{14}$ Studies on both human autopsy and animal material suggest that dilatation of the atherosclerotic coronary artery lesion is achieved primarily by splitting of the atheromatous plaque. ${ }^{15}$ Hence, when splinting is relieved as a result of balloon inflation, the stenosis may be largely eliminated. Further dilatations may reduce the elastic recoil of the media and adventitia by simple stretching and injury to the smooth-muscle cells of the media. ${ }^{16}$ Remarkably this procedure only rarely causes significant embolization of atherosclerotic debris into the distal coronary artery. ${ }^{17}$ Splitting of the plaque gives rise to the frequent angiographic appearance of a localized dissection at the site of successful dilatation. It is unusual for the dissection to extend and compromise the arterial lumen.

The mechanism of healing of the dilated, and hence injured, atherosclerotic segment is rather less completely understood. A combination of dissolution of atheroma and fibrous retraction may contribute to the normalization of the appearance of the dilated segment and, in some cases, cause a further increase in lumen size. If reendothelialization of the enlarged lumen occurs then a successful dilatation is likely to persist. However, the process of healing commonly appears to accelerate local atherosclerosis and may in part explain the high incidence of restenosis after successful dilatation. This 'response to injury' mechanism of atherogenesis may also explain a similar high incidence of recurrence at the site of dilatation of non-critical lesions ${ }^{18}$ Restenosis continues to occur in $30 \%$ of cases in most series. A knowledge of the mechanisms involved would appear to be pertinent to this problem. 


\section{Technique}

PTCA is a complex procedure based on the principles of cardiac catheterization. The procedure requires a trained operator and team, appropriate laboratory facilities and equipment, and usually cardiothoracic surgical cover. A well defined operator learning curve has been described ${ }^{19}$ and has been shown to be modified by the introduction of newer catheter systems. ${ }^{20}$

The choice between femoral artery Seldinger puncture and brachial arteriotomy is based on a combination of the previous experience and preference of the operator, vascular access available in the patient and on the site of the lesion to be dilated. ${ }^{21}$ Stability and extent of coronary intubation and guide wire manoeuverability vary with the approach used. As a general rule, right coronary lesions and saphenous vein grafts are more easily tackled using the brachial approach; circumflex by the femoral approach, and left anterior descending by either method.

The basic method most commonly consists of:

(1) Right heart catheterization with a bipolar pacing catheter positioned so that ventricular pacing may be initiated, should the need arise.

(2) Left heart catheterization and selective coronary angiography (providing the pre-dilatation images).

(3) Insertion of a guiding catheter and engagement within the coronary ostium.

(4) Passage of the balloon catheter into the coronary artery via the guiding catheter (usually preceded by its central steerable guide wire).

(5) Positioning of the balloon at the site of the stenosis.

(6) Multiple inflations of the balloon of different durations and pressures.

(7) Withdrawal of the balloon and guiding system, and repeat coronary angiography (providing the post-dilatation images). (Figure 1).

In addition, nitrates and calcium antagonists may be given around the time of the procedure in an attempt to reduce the incidence of coronary arterial spasm. $\beta$-blockers are usually withdrawn for the same reason. In order to reduce the risk of thrombosis, rheomacrodex is usually infused during the procedure and the patient is fully anti-coagulated with heparin. Anti-platelet agents may be given together with calcium antagonists for several months after the PTCA, although there is no evidence that this reduces the incidence of restenosis.

The original balloon catheter, introduced by Schneider-Medintag, consists of a double lumen catheter; the outer lumen communicating with the balloon. The central lumen, which communicates with the end-hole, enables the monitoring of pressure distal to the balloon, and the injection of contrast material and drugs into the distal coronary artery. A $9 \mathrm{~mm}$ fixed wire extends from the tip and may be either straight or curved. The catheters are available with balloons of different diameters and lengths.

The movable, independent guide-wire system introduced in 1979 provided a number of significant advantages over the fixed wire systems ${ }^{22}$ and has consequently increased the success rate and safety of the procedure. ${ }^{23}$ The guide-wire is passed through the central lumen of the balloon catheter so that its tip may be manipulated to provide a guide for the advancing balloon. The 'steerable' wire is so called by virtue of its ' $J$ '-shaped tip which may be rotated within the coronary artery by applying torque to the other end. By rotating and advancing the wire, it may be 'steered' into the required branch of the coronary tree, thus allowing access to previously inaccessable lesions. A number of movable guide wires are currently available, each with different characteristics. ${ }^{24} \mathrm{~A}$ long 'exchange wire' allows exchange of balloon catheters while the wire itself remains in position across the lesion, removing the need to recross difficult lesions.

More recently, improvements in manufacturing technique have brought the introduction of a number of 'low-profile' balloons. These have increased the proportion of lesions crossed and hence improved primary success rates. ${ }^{11}$

Guiding catheters are largely modelled on their smaller selective coronary and multipurpose catheter? counterparts. The larger diameter guiding catheter is more likely to occlude or damage the coronary ostium. The new generation guiding catheters, however, tend to be smaller and are available with soft-tips and distal side holes. The optimal selection and manipulation of the guiding catheter is vital to the technique of crossing the stenosis with the balloon..$^{25}$

The choice of appropriate guiding catheter, balloon catheter and guide-wire for a particular procedure is becoming increasingly wide and depends on the vessel, the site and characteristics of the lesion and the experience of the operator.

The number, duration and pressure of balloon inflations are determined by many factors. The number of inflations depends largely on evidence of successful dilatation, i.e. a fall in pressure gradient across the lesion, or angiographic evidence of reduction of the stenosis. There is evidence that long inflation times (of one minute or longer) may improve results. ${ }^{26}$ The duration of inflation is frequently limited by chest pain or other evidence of myocardial ischaemia, such as ST segment elevation or left-ventricular dysfunction. In our unit $31 \%$ of patients have required diamorphine during the procedure. It has been shown that regional myocardial dysfunction may occur with as little as 20 seconds of balloon inflation. ${ }^{27}$ The inflation pressure is usually increased until a 

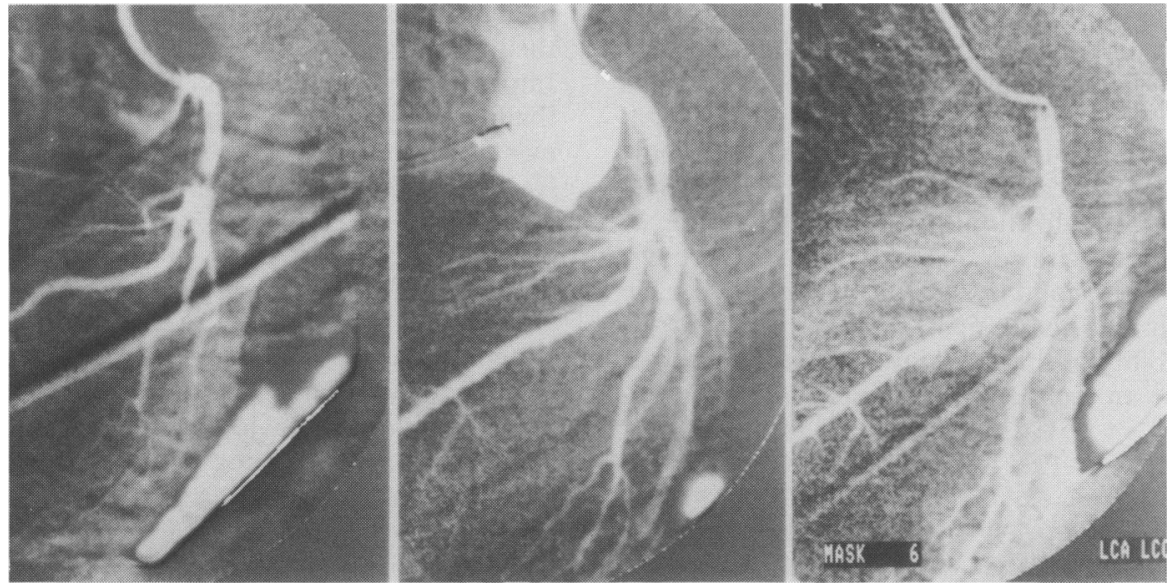

Figure 1 Digital subtraction coronary angiograms from a patient undergoing successful dilatation of a left anterior descending coronary artery stenosis, before (left), immediately after (centre) and 14 months after PTCA (right). Immediately following PTCA both the lumen diameter and the pixel density (below) are improved. Fourteen months after PTCA the coronary arteriogram at the site of the lesion appears to be normal.

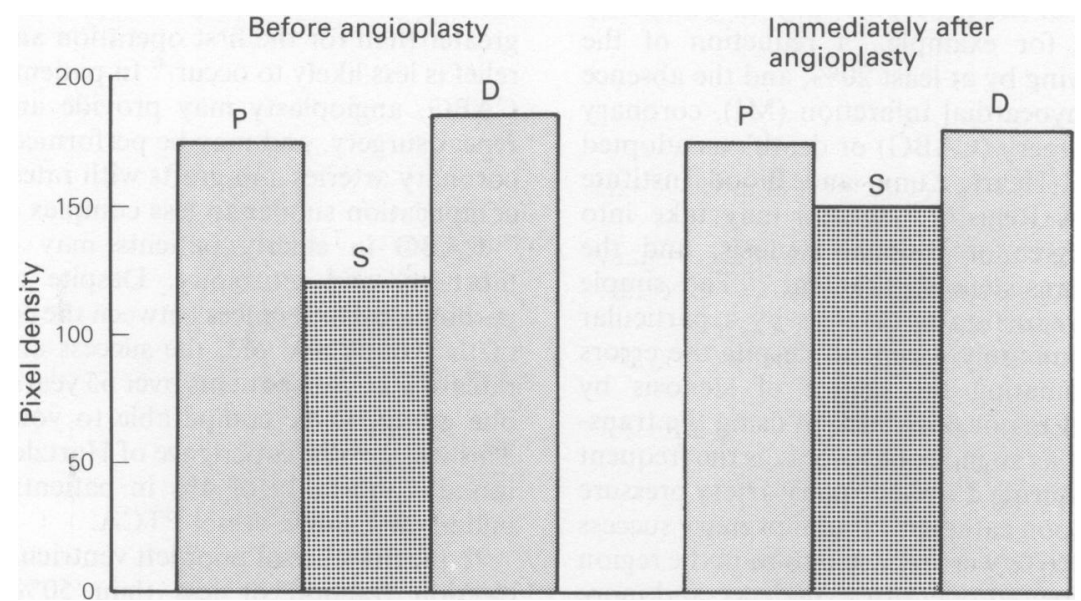

Coronary artery pixel density proximal to the stenosis (P), at the site of stenosis (S) and distal to the stenosis (D). There is a significant improvement in the pixel density at the site of the stenosis following PTCA $(P<0.05)$.

satisfactory result is obtained. However, there is a risk of balloon rupture at high pressures.

An important element in successful PTCA is the quality of X-ray screening and the ability to store still frames for continuous display, using either video, photographic, or digital images.

Lesions involving, or near to, an important bifurcation were originally thought, because of the risk of iatrogenic occlusion of one of the branches, to be a contraindication to PTCA. Double balloon techniques (the so-called 'kissing balloon' technique) may be used with safety in such cases. ${ }^{28,29}$ The insertion of the second guiding catheter inevitably carries an increased risk of complications at the site of arterial puncture. An alternative method is to pass a second guide wire through the original guiding catheter to be positioned in the side branch at risk while dilatation of the main vessel is performed (the so-called 'protective' guide wire technique). ${ }^{30}$ The second guide wire may then be used to guide balloon access to the side branch in the event of occlusion.

Technical improvements in angioplasty equipment 
continue to improve success rates. Attention recently has been turned towards protection of the ischaemic myocardium distal to the inflated balloon. Catheters which allow the perfusion of arterial blood into distal artery are now available, and there has been some interest in coronary sinus retroperfusion techniques.

Successful recanalization, by argon laser probe, of coronary arteries with severe stenoses, which are not traversable with standard PTCA techniques, have recently been reported in man. ${ }^{12,13}$ While demonstrating the feasibility of this technique, it is apparent that there may be an increased risk of spasm and thrombosis.

\section{Results}

The definition of successful PTCA differs widely between institutions. When examining the success of PTCA, consideration is made of the primary success of the procedure itself, including the absence of complications, improvement in myocardial ischaemia, and of symptomatic improvement of the patient. The primary success of the procedure may be defined by several criteria, for example, 'a reduction of the diameter narrowing by at least $20 \%$, and the absence of in-hospital myocardial infarction (MI), coronary artery bypass surgery (CABG) or death', as adopted by the National Heart, Lung, and Blood Institute (NHLBI) PTCA Registry. ${ }^{10}$ Others may take into account the degree of residual stenosis, and the reduction in trans-stenotic gradient. ${ }^{31}$ The simple definition of a reduction in stenosis by a particular percentage is commonly accepted, despite the errors inherent in estimating the degree of stenosis by angiography. ${ }^{32} \mathrm{~A}$ major drawback of using the transstenotic gradient as an index of success, is the frequent difficulty in measuring distal coronary artery pressure through the balloon catheter. ${ }^{33}$ Initial primary success rates in the late 1970s were reported to be in the region of $60 \%$, but increased operator experience and more advanced equipment and techniques have lead to primary success in excess of $90 \%{ }^{34}$

Assessment of multiple lesion PTCA is more complicated, as primary success may be achieved in some but not all attempted lesions. Improvement in angina may occur in this group even when not all attempted lesions are successfully dilated. ${ }^{35}$ Some would define success, in this group, as when either all attempted lesions are successfully dilated, or the consideredcritical-stenosis is successfully dilated and there was clinical improvement. ${ }^{36}$ Varying definitions of success make the direct comparison of different reported series difficult and often impossible.

Both symptomatic, and objective exercise test criteria of ischaemia have been shown to improve following primary successful PTCA; $90 \%-96 \%$ of patients can be expected to experience improvement in their symptoms following successful PTCA. ${ }^{31,37,38}$ Improvement in exercise electro-cardiography, ${ }^{31,38-40}$ thallium myocardial scintigraphy, ${ }^{39,40}$ and improvement in radionuclide cineangiographic exercise ejection fraction $^{39}$ have all been observed.

\section{Complex PTCA}

Initial experience was limited to single vessel dilatation in patients with single vessel coronary artery disease. Multiple lesions, distal lesions, left main-stem stenosis, eccentric stenoses, poor left-ventricular function, acute myocardial infarction and advanced age were all considered contraindications to PTCA. With increased operator experience and improved catheter systems, multiple dilatations in patients with multivessel disease have been performed with a high degree of success and a low complication rate. ${ }^{24,36,41,42}$

The progression of native coronary artery disease and stenosis of grafts causes a recurrence of angina in many patients with previous successful CABG.$^{43,44}$ The morbidity and mortality of repeat CABG are both greater than for the first operation and symptomatic relief is less likely to occur. ${ }^{45}$ In patients with previous CABG, angioplasty may provide an alternative to repeat surgery, and may be performed in both native coronary arteries and grafts with rates of success an complication similar to less complex cases. ${ }^{42,46,47}$

CABG in elderly patients may carry a higher mortality and morbidity. Despite anatomical and pathological differences between the coronary arteries of the young and old, the success and complication rates of PTCA in patients over 65 years were found, by one group, to be comparable to younger patients. ${ }^{48}$ This was not the experience of Hartzler's group ${ }^{42}$ who found a mortality of $4 \%$ in patients over 70 years undergoing single vessel PTCA.

In the presence of poor left ventricular function (i.e. ejection fraction of less than $50 \%$ ), and despite comparable angiographic success rates when compared to patients with normal left-ventricular function, there is an associated higher morbidity and mortality. ${ }^{49}$

Angioplasty to left main-stem stenoses remains a high risk procedure. However, it may be considered in patients who are inoperable, who have isolated mainstem disease, or who have patent grafts to the left coronary circulation, and in patients with good collateral supply from the right coronary artery. ${ }^{42}$ Intra-aortic balloon pump insertion and relatively short dilatation times are advisable in these cases. With these precautions, left main-stem stenoses may be successfully dilated although not always as completely as other vessels. ${ }^{42}$

In patients with unstable angina refactory to 
medical therapy, PTCA may be performed with safety, and with an 80 to $90 \%$ primary success rate. ${ }^{50,51}$ PTCA is effective in both the short term and long term improvement of angina in this group.

\section{PTCA in acute myocardial infarction}

In an attempt to reduce infarct size and mortality, there is a great deal of current interest in intervention in acute myocardial infarction. Numerous studies have been published on the effects of either intravenous or intracoronary streptokinase, and more recently of human tissue-type plasminogen activator (t-PA). Such fibrinolytic therapy is proven to reopen obstructed arteries, but in approximately $90 \%$ of cases critical stenoses remain at the site of occlusion. These residual stenoses have the potential for causing further myocardial ischaemia, reocclusion and reinfarction. Several studies have been made on the rôle of PTCA either as an adjunct to thrombolysis in the acute phase of myocardial infarction, or as a means of primary reperfusion of the infarct related vessel. ${ }^{52-56}$ Successful dilatation is achieved with the combination of thrombolysis and PTCA in $77-88 \%$ of cases in the acute phase of myocardial infarction. Despite the use of thrombolytic agents, transient peripheral coronary embolization may be seen in $12 \%$ of cases $^{54}$ and early (in hospital) reocclusion occurs in $6-16 \% .{ }^{53-56}$ It is commonly agreed that during acute myocardial infarction only the infarct-related vessel should be dilated and any further stenoses should be tackled on a subsequent occasion. If a vessel remote from the site of infarction were to become occluded, causing a second infarction, the result would be likely to be fatal; hence the attempt of unrelated lesions carries an excessive risk.

\section{Restenosis}

In Gruentzig's series, follow-up of patients over 2 to 5 years revealed a restenosis rate of $25 \%$, with all recurrences occuring within the first 9 months after PTCA. ${ }^{9}$ The NHLBI PTCA registry reported a restenosis rate of $33.6 \% .{ }^{18}$ It is of interest to note that restenosis was found in $56 \%$ of patients with recurrent angina and in only $14 \%$ of patients without angina after PTCA.

The most common histological finding at the site of restenosis is that of intimal hyperplasia. ${ }^{57}$ The exact mechanism by which restenosis occurs remains obscure. There are suggestions that a significant reduction in trans-stenotic gradient and the presence of a small intimal dissection may reduce the incidence of restenosis. ${ }^{58}$ In addition, the use of too small a balloon may be implicated in an increased incidence of recurrent stenosis. ${ }^{59}$ This observation may in part explain the different risk of restenosis in left anterior descending (LAD) and right coronary artery lesions. Spasm at the site of successful dilatation may also be relevant to the genesis of restenosis. ${ }^{60}$

Recurrent stenosis at the site of dilatation remains a significant problem which has yet to be overcome. Studies have been made on the effect of aspirin, sulphinpyrazone, dipyridamole, anticoagulants and calcium antagonists on restenosis, but as yet no firm conclusion can be drawn other than that several more suitable clinical trials are required..$^{59}$ Although recurrent stenosis remains common, it is clear that a second PTCA may be performed with a higher success rate and fewer complications than for initial procedures. ${ }^{61}$ The recurrence rate following a second PTCA is the same as for the first, and it has therefore been recommended that 'repeat PTCA for patients with restenosis should be an integral component of PTCA therapy'.

\section{Socio-economic considerations}

Despite the vast expense, coronary artery bypass surgery (CABG) has been shown, in the USA, to be a more cost-effective form of treatment than medical therapy alone. ${ }^{62}$ When compared with CABG, PTCA is significantly less expensive and involves a shorter stay in hospital. ${ }^{63}$ With a primary success rate of $80 \%$ for PTCA, it has been estimated that surgery is 1.9 times more expensive than PTCA.$^{63}$ This calculation is, of course, based on a comparison of the costs of single procedures. As already discussed, in view of the currently observed rate of restenosis, PTCA should be regarded as a multi-procedure treatment; a fact that complicates the direct comparison of costs and when taken into account reduces this cost-benefit ratio. ${ }^{64}$ There is yet another economic factor to consider. If patients undergo PTCA who might not otherwise have been referred for surgery, then PTCA may actually add to the national bill for interventional treatment of coronary artery disease.

Clearly, comparison of the costs of PTCA and CABG should take into account both the material cost of the procedure itself and the broader economic implications of a shorter convalescence and an earlier return to work. Psychosocial adjustment of patients following PTCA has been shown to be significantly better than in patients following coronary artery bypass surgery. ${ }^{65}$ Six months following PTCA, patients were functioning better at work, with their families, and in sexual performance. Problems of anxiety, depression and somatic complaints tend to subside much earlier in patients following PTCA than those undergoing CABG. The return to work of a patient following PTCA may depend on a number of 
factors, including whether the patient was working up to the time of the PTCA, the type of work, the socioeconomic environment, the presence of angina, and the number of tablets taken. ${ }^{66}$ In those patients who were working right up to the time of PTCA 81 to $86 \%$ were working at the time of follow-up (mean time since PTCA: 1.4 years). Whether or not the patient returned to work was independent of the success of the PTCA. However, those undergoing successful PTCA returned to work significantly sooner.

\section{Complications}

PTCA carries a significant risk of complications. These are most frequently acute coronary events resulting from coronary artery dissection and occlusion, but less commonly include arrhythmias, coronary embolism, coronary perforation, tamponade, problems at the site of vascular access and bleeding.

In over three thousand patients reported by the NHLBI registry ${ }^{67}$ the incidence of major complications (i.e. death, non-fatal myocardial infarction, emergency surgery) was $9.4 \%$. Non-fatal MI occurred in $5 \%$, the mortality was $0.9 \%$, and emergency surgery without death or infarction was performed in $3.4 \%$. In all, $6.6 \%$ of patients were referred for emergency surgery, of whom $6.4 \%$ died and $25 \%$ developed trans-mural myocardial infarction. ${ }^{68}$ Coronary arterial spasm was reported in $5 \%$ of the patients in the NHLBI registry; a complication rarely seen in our experience.

In the combined experience of 609 procedures recently reported by two centres in this country, ${ }^{31,69}$ myocardial infarction, emergency surgery and death, occurred in $5.5 \%, 6 \%$ and $1 \%$ respectively. While these figures include the early experience of these operators, they must be taken as representing the current complication rate for PTCA in this country. However, increased operator experience does appear to reduce the incidence of major complications. ${ }^{70}$

In early experience with PTCA, emergency surgery was used whenever a major complication occurred. Referral for emergency CABG is now influenced more by the personal preference of the cardiologist. In view of the complication rate of emergency surgery, many now manage acute coronary events either conservatively, if the patient's condition is stable, or with repeat angiography leading to repeat angioplasty if appropriate. ${ }^{71}$ Clearly in certain cases there may be no alternative to emergency CABG.

\section{Conclusions}

The wealth of worldwide experience with PTCA, to date, provides reliable data concerning the use of this procedure in patients presenting with different facets of the spectrum of coronary artery disease. As we have shown, rates of success, the probability of the relief of symptoms, complication rates, and the rate of restenosis, have been well established. However, the state of the art leaves a number of significant unanswered questions.

Firstly, the problem of restenosis. In order to address this problem we will need to know more about the mechanism of restenosis, and examine possible means of dealing with it. There are suggestions that the size of balloon, and the number and duration of inflations may be important. It is also possible that anti-platelet and anti-spasm drugs may be of benefit. All these will need to be examined in properly conducted controlled clinical trials.

Secondly, despite the knowledge gained from the treatment of many thousands of patients worldwide, the indications for PTCA remain imprecise. We know that PTCA is effective at relieving angina in patients with anatomy that is technically suitable ("balloonable'), but beyond this several pertinent questions remain: (1) What are the long term effects of PTCA on mortality and future coronary events, and how does this compare with surgery? (2) Is a patient witlp mild symptoms and single vessel disease better treated by PTCA than medically? (3) In patients with failed medical therapy and single vessel disease, is an internal mammary graft better than PTCA? (4) Does PTCA merely postpone surgery, and, if by doing so, does it influence the long term expectations of the individual patient? (5) In patients with multiple lesions, should we be attempting the same degree of revascularization as would be achieved surgically, or should we attempt only those lesions responsible for regional ischaemia?

Clearly there is enormous scope for prospective randomized trials comparing PTCA with CABG and medical therapy. It is necessary to compare the extent and duration of the relief of symptoms, the effect on the patient's life-style, the mortality, the frequency of coronary events, the frequency of second procedures, and the cumulative cost. As in any other situation where the possibility of controlled trials exist, it is inadequate to rely on anecdotal evidence and personal experience. 
References

1. Judkins, M.P. Selective coronary arteriography. 1. A percutaneous transfemoral technic. Radiology 1967, 89: $815-824$.

2. Amplatz, K., Formanek, G., Stranger, P. \& Wilson, W. Mechanics of selective coronary artery catheterisation via femoral approach. Radiology 1967, 89: 1040-1047.

3. Ricketts, J.H. \& Abrams, H.L. Percutaneous selective coronary cine arteriography. JAMA 1962, 181: 620-624.

4. Sones, F.M. Jr. \& Shirey, E.K. Cine coronary arteriography. Mod Conc Cardiovasc Dis 1962, 31: 735-738.

5. Garrett, H.E., Dennis, E.W. \& De Bakey, M. Aortocoronary bypass with saphenous vein graft. Seven-year follow-up. JAMA 1973, 223: 792-794.

6. Green, G.E. Internal mammary artery to coronary artery anastomosis: Three year experience with 165 patients. Ann Thorac Surg 1972, 14: 260-271.

7. Dotter, C.T. \& Judkins, M.P. Transluminal treatment for arteriosclerotic obstruction: description of a new technic and a preliminary report of its application. Circulation 1964, 30: 654-670.

8. Gruentzig, A.R. Transluminal dilatation of coronary artery stenosis. Lancet 1978, i: 263.

9. Gruentzig, A.R. \& Meier, B. Percutaneous transluminal coronary angioplasty. The first five years and the future. Int J Cardiol 1983, 2: 319-323.

10. Detre, K.M., Myler, R.K., Kelsey, S.F., van Raden, M., To, T. \& Mitchell, H. Baseline characteristics of patients in the National Heart, Lung, and Blood Institute Percutaneous Transluminal Coronary Angioplasty Registry. Am J Cardiol 1984, 54: 7C-11C.

11. Anderson, H.V., Roubin, G.S., Leimgruber, P., Douglas, J.S., King, S.B. \& Gruentzig, A.R. Primary angiographic success rates of percutaneous transluminal coronary angioplasty. Am J Cardiol 1985, 56: 712-717.

12. Cumberland, D.C., Oakley, G.D.G., Smith, G.H. et al. Percutaneous laser-assisted coronary angioplasty. Lancet 1986, ii: 214.

13. Crea, F., Davies, G., McKenna, W., Pashazade, M., Taylor, K. \& Maseri, A. Percutaneous laser recanalisation of coronary arteries. Lancet 1986, ii: 214-215.

14. Fallon, J.T. Pathology of arterial lesions amenable to percutaneous transluminal angioplasty. Am J Radiol 1980, 135: 913-916.

15. Block, P.C. The mechanism of transluminal angioplasty. In: Ischinger, T. (ed) Practice of Coronary Angioplasty. Springer-Verlag, Berlin, 1986, pp4-14.

16. Mizuno, K., Kurita, A. \& Imazeki, N. Pathological findings after percutaneous transluminal coronary angioplasty. Br Heart Journal 1984, 52: 588-590.

17. Block, P.C., Elmer, D. \& Fallon, J.T. Release of atherosclerotic debris after transluminal angioplasty. Circulation 1982, 65: 950-952.

18. Holmes, D.R., Vliestra, R.E., Smith, H.C. et al. Restenosis after percutaneous transluminal coronary angioplasty (PTCA): a report from the PTCA registry of the National Heart, Lung, and Blood Institute. Am J Cardiol 1984, 53: 77C-81C.

19. Kelsey, S.F., Mullin, S.M., Detre, K.M. et al. Effect of experience on percutaneous transluminal coronary angioplasty. Am J Cardiol 1984, 53: 56C-64C.

20. Feit, A., Reddy, C.V.R., Khan, R., Meilman, H. \& El-
Sherif, N. Changed learning curve for percutaneous transluminal coronary angioplasty. Am J Med 1985, 78: $438-442$.

21. Dorros, G. Technique of PTCA by the brachial approach: practical considerations and comparison with the femoral artery method. In: Ischinger, T. (ed) Practice of Coronary Angioplasty. Springer-Verlag, Berlin, 1986, pp 166-182.

22. Simpson, J.B., Baim, D.S., Robert, E.W. \& Harrison, D.C. A new catheter system for coronary angioplasty. Am J Cardiol 1982, 49: 1216-1222.

23. Harston, W.E., Tilley, S., Rodeheffer, R., Forman, M.B. \& Perry, J.M. Safety and success of the beginning percutaneous transluminal coronary angioplasty programme using the steerable guidewire system. $\mathrm{Am} \mathrm{J}$ Cardiol 1986, 57: 717-720.

24. Vandormael, M., Ischinger, T. \& Roth, R. Angioplasty equipment and supplies: technical considerations. In: Ischinger T. (ed) Practice of Coronary Angioplasty. Springer-Verlag, Berlin, 1986, pp 93-127.

25. Carr, M.L. The use of the guiding catheter in coronary angioplasty: the technique of manipulating catheters to obtain the necessary power to cross tight coronary coronary stenoses. Cathet Cardiovasc Diagn 1986, 12: 189-197.

26. Kaltenbach, M., Beyer, J., Walter, S., Klepzig, H. \& Schmidts, L. Prolonged application of pressure in transluminal coronary angioplasty. Cathet Cardiovasc Diagn 1984, 10: 213-219.

27. Norrell, M.S., Lyons, J., Gardener, J., Layton, C. \& Balcon, R. Detection of myocardial ischaemia during coronary angioplasty: limitation of ECG monitoring. Br Heart $J$ 1987, 57: 89.

28. Zack, P.M. \& Ischinger, T. Experience with a technique for coronary angioplasty of bifurcational lesions. Cathet Cardiovasc Diagn 1984, 10: 433-443.

29. George, B.S., Myler, R.K., Stertzer, S.H. et al. Balloon angioplasty of coronary bifurcation lesions: The Kissing Balloon Technique. Cathet Cardiovasc Diagn 1986, 12: 124-138.

30. Oesterle, S.N., McAuley, B.J., Buchbinder, M. \& Simpson, J.B. Angioplasty at coronary bifurcations: single guide, two-wire technique. Cathet Cardiovasc Diagn 1986, 12: 57-63.

31. Sowton, E., Timmis, A., Crick, J., Griffin, B., Yates, A. \& Deverall, P. Early results after percutaneous transluminal coronary angioplasty in 400 patients. Br Heart $J$ 1986, 56: 115-120.

32. Giuliani, E.R. Percutaneous transluminal angioplasty. JACC 1985, 6: 992-994.

33. Meier, B. \& Ischinger, T. Assessment of results of coronary angioplasty. In: Ischinger T. (ed) Practice of Coronary Angioplasty Springer-Verlag, Berlin, 1986, pp 183193.

34. Meier, B. \& Gruentzig, A.R. Learning curve for percutaneous transluminal coronary angioplasty: skill, technology or patient selection. Am J Cardiol 1984, 53: 65C66C.

35. Vandormael, M.G., Chaitman, B.R., Ischinger, T. et al. Immediate and short-term benefit of multilesion coronary angioplasty: influence of degree of revascularization. 
J Am Coll Cardiol 1985, 6: 983-991.

36. Dorros, G., Stertzer, S.H., Cowley, M.J. \& Myler, R.K. Complex coronary angioplasty: multiple coronary dilatations. Am J Cardiol 1984, 53: 126C-130C.

37. Mabin, T.A., Holmes, D.R., Smith, H.C. et al. Followup clinical results in patients undergoing percutaneous transluminal coronary angioplasty. Circulation 1985, 71: 754-760.

38. Berger, E., Williams, D.O., Reinert, S. \& Most, A.S. Sustained efficacy of percutaneous transluminal coronary angioplasty. Am Heart J 1986, 111: 233-236.

39. Rosing, D.R., van Raden, M.J., Mincemoyer, R.M. et al. Exercise, electrocardiographic and functional responses after percutaneous transluminal angioplasty. Am J Cardiol 1984, 53: 36C-41C.

40. Scholl, J.M., Chaitman, B.R. \& David, P.R. Exercise electrocardiography and myocardial scintigraphy in the serial evaluation of the results of percutaneous transluminal coronary angioplasty. Circulation 1982, 66: 380-390.

41. Cowley, M.J., Vetrovec, G.W., DiSciascio, G., Lewis, S.A., Hirsh, P.D. \& Wolfgang, T.C. Coronary angioplasty of multiple vessels: short-term outcome and longterm results. Circulation 1985, 72: 1314-1320.

42. Hartzler, G.O. Complex coronary angioplasty: multiplevessel/multiple-lesion dilatation. In: Ischinger T. (ed) Practice of Coronary Angioplasty Springer-Verlag, Berlin, 1986, pp 250-266.

43. Loop, F.D., Sheldon, W.C., Lytle, B.W., Cosgrove, D.M. \& Proudfit, W.L. The efficacy of coronary artery surgery. Am Heart J 1981, 101: 86-96.

44. Seides, S.F., Borer, M.D., Kent, K.M., Rosing, D.R., McIntosh, C.L. \& Epstein, S.E. Long term anatomic fate of coronary artery bypass grafts and functional status of patients five years after operation. N Engl J Med 1978, 298: 1213-1217.

45. Reul, G.J., Cooley, D.A., Ott, D.A., Ceolho, A., Chapa, L. \& Eterovic, I. Reoperation for recurrent coronary artery disease. Arch Surg 1979, 114: 12691275.

46. Corbelli, J., Franco, I., Hollman, J., Simpfendorfer, C. \& Galan, K. Percutaneous transluminal coronary angioplasty after previous coronary artery bypass surgery. Am J Cardiol 1985, 56: 398-403.

47. Ineson, N., Cooper, I.C. \& Webb-Peploe, M.M. Percutaneous transluminal angioplasty in patients with previous coronary artery bypass graft surgery. Br Heart J 1987, 57: 89.

48. Riazner, A.E., Hust, R.G., Lewis, J.M., Winters, W.L. Jr., Batly, J.W. \& Roberts, R. Transluminal coronary angioplasty. Am J Cardiol 1986, 57: 29-32.

49. Bentivoglio, L.G., Van Raden, M.J., Kelsey, S.F. \& Detre, K.M. Percutaneous transluminal coronary angioplasty (PTCA) in patients with relative contraindications: results of the National Heart, Lung, and Blood Institute PTCA registry. Am J Cardiol 1984, 53: 82C88C.

50. Quigley, P.J., Erwin, J., Maurer, B.J., Walsh, M.J. \& Gearty, G.F. Percutaneous transluminal coronary angioplasty in unstable angina: comparison with stable angina. Br Heart $J$ 1986, 55: 227-230.

51. de Feyter, P.J., Serruys, P.W., van den Brand, M. et al. Emergency coronary angioplasty in refractory unstable angina. $N$ Engl J Med 1985, 313: 342-346.

52. Meyer, J., Merx, W., Schweizer, P. et al. Advantages of combining transluminal coronary angioplasty (PTCA) with selective coronary thrombolysis in acute infarction. Circulation 1982, 66 (suppl ii): 261.

53. Hartzler, G.O., Rutherford, B.D. \& McConahay, D.R. Percutaneous transluminal coronary angioplasty: application for acute myocardial infarction. Am J Cardiol 1984, 53: 117C-121C.

54. Erbel, R., Pop, T., Meinertz, T. et al. Combined medical and mechanical recanalisation in acute myocardial infarction. Cathet Cardiovasc Diagn 1985, 11: 361-377.

55. Topol, E.J., Eha, J.E., Brin, K.P. et al. Applicability of percutaneous transluminal coronary angioplasty to patients with recombinant tissue plasminogen activator mediated thrombosis. Cathet Cardiovasc Diagn 1985, 11: 337-348.

56. Prida, X.E., Holland, P., Feldman, R.L. et al. Percutaneous transluminal coronary angioplasty in evolving acute myocardial infarction. Am J Cardiol 1986, 57: 1069-1074.

57. Essed, C.E., Van den Brand, M. \& Becker, A.E. Transluminal coronary angioplasty and early restenosis. Fibrocellular occlusion after wall laceration. Br Heart J 1983, 49: 393-396.

58. Leimgrubber, P.P., Roubin, G.S., Anderson, H.V. et al. Influence of intimal dissection on restenosis after successful coronary angioplasty. Circulation 1985, 72: 530535.

59. Hollman, J. \& Ischinger, T. The problem of restenosis In: Ischinger T. (ed) Practice of Coronary Angioplast ys $^{-}$ Springer-Verlag, Berlin 1986, pp 211-222.

60. Quyyumi, A.A., Raphael, M., Perrins, E.J., Shapiro, L.M., Rickards, A.F. \& Fox, K.M. Incidence of spasm at the site of previous successful transluminal coronary angioplasty: effect of ergometrine maleate in consecutive patients. Br Heart $J$ 1986, 56: 27-32.

61. Williams, D.O., Gruentzig, A.R., Kent, K.M., Detre, K.M., Kelsey, S.F. \& To, T. Efficacy of repeat percutaneous transluminal coronary angioplasty for coronary restenosis. Am J Cardiol 1984, 53: 32C-35C.

62. Weinstein, M.C. \& Stason, W.B. Cost-effectiveness of coronary artery bypass surgery. Circulaton 1982,66 : iii56 - iii-66.

63. Jang, G.C., Block, P.C., Cowley, M.J. et al. Relative cost of coronary angioplasty and bypass surgery in a onevessel disease model. Am J Cardiol 1984, 53: 52C-55C.

64. Reeder, G.S., Krishan, I., Nobrega, F.T. et al. Is percutaneous coronary angioplasty less expensive than bypass surgery? $N$ Engl J Med 1984, 311: 1157-1162.

65. Raft, D., McKee, D.C., Popio, K.A. \& Haggerty, J.J. Life adaptation after percutaneous transluminal coronary angioplasty and coronary artery bypass grafting. $\mathrm{Am}$ J Cardiol 1985, 56: 395-398.

66. Holmes, D.R., Van Raden, M.J., Reeder, G.S. et al. Return to work after coronary angioplasty: a report from the National Heart, Lung, and Blood Institute Percutaneous Transluminal Coronary Angioplasty Registry. Am J Cardiol 1984, 53: 48C-51C.

67. Cowley, M.J., Dorros, G., Kelsey, S.F., Van Raden, M. \& Detre, K.M. Acute coronary events associated with percutaneous transluminal coronary angioplasty. Am J Cardiol 1984, 53: 12C-16C. 
68. Cowley, M.J., Dorros, G., Kelsey, S.F., Van Raden, M., Detre, K.M. Emergency coronary bypass surgery after coronary angioplasty: the National Heart, Lung, and Blood Institute's percutaneous transluminal angioplasty experience. Am J Cardiol 1984, 53: 22C-26C.

69. Oakley, G.D.G. Coronary angioplasty - what can we reasonably expect? Br Heart J 1986, 55: 221-222.
70. Dorros, G. \& Cowley, M. Complications associated with PTCA. In: Ischinger T. (ed) Practice of Coronary Angioplasty. Springer-Verlag, Berlin, 1986, pp 223-240.

71. Hollman, J., Gruentzig, A., Douglas, J., King, S., Ischinger, T. \& Meier, B. Acute occlusion after percutaneous transluminal coronary angioplasty - a new approach. Circulation 1983, 68: 725-732. 